\title{
Inside the Camera Obscura: Kepler's Experiment and Theory of Optical Imagery
}

\author{
Sven Dupré* \\ Ghent University
}

\begin{abstract}
In his Paralipomena (1604) Johannes Kepler reported an experimentum that he had seen in the Dresden Kunstkammer. In one of the rooms there, which had been turned in its entirety into a camera obscura, he had witnessed the images formed by a lens. I discuss the role of this experiment in the development and foundation of his new theory of optical imagery, which made a distinction between two concepts of image, pictura and imago. My focus is on how Kepler used his report of the experiment inside the camera obscura to criticize the account of image formation given in Giovanbattista Della Porta's Magia naturalis (1589). I argue that this experiment allowed Kepler to sort out the confusion between images 'in the air'-referring to the geometrical locus of images in the perspectivist tradition of optics - and the experimentally produced 'projected images', which were empirically familiar but conceptually alien to perspectivist optics.
\end{abstract}

\section{Keywords}

Johannes Kepler, Giovanbattista Della Porta, Jean Pena, experiment, natural magic, image in the air, Kunstkammer, camera obscura, Dresden, optical imagery, play

\footnotetext{
*) The author is a Postdoctoral Research Fellow of the Research Foundation-Flanders. This work was partially funded by a Visiting Fellowship in the Sydney Centre for the Foundations of Science at the University of Sydney and by a Research Grant of the Research Foundation-Flanders. Previous and partial versions of this paper were presented at the workshop "Inside the Camera Obscura," organized by Sven Dupré, Wolfgang Lefèvre, and Carsten Wirth at the Max Planck Institute for the History of Science (Berlin) in July 2006 and at the workshop "Optics and Epistemology" at the Unit for History and Philosophy of Science at the University of Sydney in July 2007. I would like to thank the participants and audiences of these workshops for their valuable comments and suggestions.
} 


\section{Introduction}

In his Paralipomena (1604) Johannes Kepler mentioned

an experimentum ... which I saw at Dresden in the elector's theater of artifices ... A disk thicker in the middle, or a crystalline lens, a foot in diameter, was standing at the entrance of a closed chamber against a little window, which was the only thing that was open, slanted a little to the right. Thus when the eyesight travelled through the dark emptiness, it also, fortuitously, hit upon the place of the image, nearer, in fact, than the lens. And so since the lens was weakly illuminated, it did not particularly attract the eyes. But the walls were also not particularly conspicuous through the lens, because they were in deep darkness. ${ }^{1}$

In one of the rooms of the Dresden Kunstkammer, which had been turned into a room-size camera obscura, Kepler witnessed the images formed by a lens placed in the aperture of this camera obscura, which, in fact, was one of the little windows of the Kunstkammer room through which light from outside was able to enter. In this darkened room Kepler saw that "the little window and the objects standing about it, which had the benefit of much light, lying hidden beyond the lens, set up a bright image of themselves in the air (between me and the lens)." ${ }^{2}$

The historiographical debate surrounding Kepler's Paralipomena has mainly concentrated on the issue of continuity or revolution. On the one hand, Stephen Straker has argued that Kepler's optics represents a mechanistic view-developed in dialogue with an artistic tradition-which breaks away from the medieval perspectivist tradition. ${ }^{3}$ On the other hand, David Lindberg has argued that

1) Johannes Kepler, Gesammelte Werke, ed. Walther von Dyck, Max Caspar, Franz Hammer, 19 vols. (Munich, 1937-), 2: 164-165. Translation in Johannes Kepler, Optics: Paralipomena to Witelo \& Optical Part of Astronomy, trans. William H. Donahue (Sante Fe, 2000), 194.

2) Kepler, Gesammelte Werke, 2: 165. Translation in Kepler, Optics, 194.

3) Stephen Mory Straker, Kepler's Optics: A Study in the Development of Seventeenth Century Natural Philosophy (Ph.D dissertation, Department of History and Philosophy of Science, Indiana University, 1971). See also the summary of his central argument in Stephen Straker, "Kepler, Tycho, and the 'Optical Part of Astronomy': The Genesis of Kepler's Theory of Pinhole Images," Archive for the History of Exact Sciences, 24 (1981), 267-293. 
Kepler is instead the culminating figure of this very same medieval perspectivist tradition. ${ }^{4}$ The debate, in fact, is about the degree of importance to be attached to the analogy between the eye and the camera obscura for Kepler's new theory of vision. While Straker has argued that Kepler's theory of the retinal image was the natural outcome of comparing the eye to a camera obscura and applying to the eye the knowledge of image-formation acquired in solving the problem of the camera obscura, Lindberg has downplayed the importance of this analogy, making the key unlocking Kepler's discovery of the retinal image his solution to the preservation of the one-to-one correspondence between points in the visual field and points in the eye, a crucial element in perspectivist optics.

Neither Straker nor Lindberg have paid attention to Kepler's experiment in the Finstergemach of the Dresden Kunstkammer. This is perhaps not surprising, since their concern was with Kepler's solution (in chapter 2 of Paralipomena) to the problem of pinhole images and with his theory of vision. The experiment inside the Dresden Kunstkammer had little to offer to Kepler's new theory of pinhole images. Nevertheless, I will argue that Kepler's experiment inside this camera obscura was important to the shaping of his argument in the Paralipomena. Kepler situated the third section of his fifth chapter, from which we have drawn Kepler's report of the experimentum, and in which he established a new concept of vision, in a place that was like the darkened room of the Dresden Kunstkammer. The experiment was important for Kepler's new response to the question of optical imagery. He distinguished two types of images: imago (or the 'perceived' image) and pictura (or the 'projected' image). ${ }^{5}$ The concept of imago was derived from perspectivist optics, but pictura was a concept of Kepler's own invention.

\footnotetext{
4) David C. Lindberg, Theories of Vision from al-Kindi to Kepler (Chicago, 1976), 178208.

5) My understanding of seventeenth-century theories of optical imagery is deeply indebted to Alan E. Shapiro, "The Optical Lectures and the Foundations of the Theory of Optical Imagery," in Mordechai Feingold, ed., Before Newton: The Life and Times of Isaac Barrow (Cambridge, 1990), 105-178. For Kepler's theory of optical imagery, see also Antoni Malet, "Keplerian Illusions: Geometrical Pictures versus Optical Images in Kepler's Visual Theory," Studies in History and Philosophy of Science, 21
} 
Although projected images were empirically familiar (for example, from the images projected inside a camera obscura for the observation of eclipses), they were conceptually alien to the medieval perspectivist tradition. ${ }^{6}$ In which ways was the experiment important for Kepler's theory?

I will argue, first, that Kepler used the experiment inside the Dresden Kunstkammer to place his reading of the theories of optical imagery in the perspectivist tradition in a courtly context. This contextualization allowed him to make the 'experiments' of image formation in Giovanbattista della Porta's Magia naturalis (1589) a point of reference and criticism. In section 1, I will show that optical texts and images of the fifteenth and sixteenth centuries confused 'experimentally' produced projected images and geometrical 'images in the air'. So did Della Porta's Magia naturalis, Kepler claimed, and he used the experiment inside the Dresden camera obscura to sort out this conceptual confusion. The immediate context of-admittedly conceptually confused-Renaissance optics was, thus, important for the generation of Kepler's theory of optical imagery. The experiment allowed him to integrate the experimentally produced projected images, which were however conceptually alien to perspectivist optics, into his new theory of optical imagery.

The experiment inside the camera obscura was also important for Kepler's theory of optical imagery in a second respect. Kepler introduced the notion of pictura to comprehend experimentally produced projected images, while he continued to use the concept of imago alongside the newly invented concept of pictura. Was this possible without creating a conceptual conflict? I will argue that the experiment inside the Dresden Kunstkammer was foundational to the co-

(1990), 1-40; A. Mark Smith, "Ptolemy, Alhazen, and Kepler and the Problem of Optical Images," Arabic Sciences and Philosophy, 8 (1998), 9-44.

6) A. Mark Smith, "Reflections on the Hockney-Falco Thesis: Optical Theory and Artistic Practice in the Fifteenth and Sixteenth Centuries," Early Science and Medicine, 10 (2005), 163-185. For a recent overview of eclipse observations inside the camera obscura in this period, see Jaroslaw Wlodarczyk, "Solar Eclipse Observations in the Time of Copernicus: Tradition or Novelty?, Journal for the History of Astronomy, 38 (2007), 351-364. 
existence of the concepts of imago and pictura and allowed Kepler to avoid an obvious conceptual ambiguity, or perhaps even contradiction, which his use of two concepts of optical image seemingly (though not for Kepler himself) introduced. In section 2, I will argue that Kepler attributed to the Dresden experimentum the status of social and intellectual play. My claim that experimental knowledge of image formation inside the camera obscura was important to the generation of Kepler's new theory of optical imagery is only valid on the condition of this historicization of the meaning of experimentum. The discussion of the pre-Keplerian confusion between 'images in the air' and projected images in section 1 and of the meaning and status of the experiment inside the camera obscura in section 2 will prepare us for the emergence of Kepler's new theory of optical imagery out of his reading of the experiments inside the camera obscura in Della Porta's Magia naturalis in section 3 of my paper.

\section{Renaissance Geometry, Experience and Physiology of Images in the Air}

In this section I will discuss three aspects of 'images in the air' in Renaissance optics. First, it will become clear that 'in the air' refers to the geometrical locus of these images. Renaissance optics, however, sometimes confused these 'images in the air' with projected images. Second, I will show that in the fifteenth and sixteenth centuries these images in the air became objects that were situated on the borderline between natural and demonic magic. Regardless of the agents of their production, the images were invariably considered to be products of the faculty of imagination. The substance of which these images were made was not thought to be light (as one might expect), but all kinds of spirits. Thirdly, I will briefly discuss the status of the 'experiments' producing images in the air and projected images as singular events disconnected from theories of optical imagery to prepare the ground for Kepler's experiment.

From Petrus Apianus to John Dee, images in the air were ubiquitous in optical texts and images of the fifteenth and sixteenth 
centuries. ${ }^{7}$ An interesting point of departure, however, for discussing these images in the air is Jean Pena's introduction to Euclid's Optica and the pseudo-Euclidean Catoptrica, De usu optices (1557), a text which was sufficiently important for Kepler to call attention to it at the beginning of his Dioptrice $(1611) .{ }^{8}$ Pena considered the uses of optical knowledge in light of the definition of optics as "ars bene videndi" or the "art of seeing-well" of his teacher, Petrus Ramus. The aim of optical knowledge was "to judge the truth and falsehood of the visible things accurately and carefully," so as to avoid being deceived by illusionist tricks which self-proclaimed sorcerers played on those ignorant of optics. ${ }^{9}$ One of the illusionist tricks which Pena mentioned in this connection made use of a mirror inside a camera obscura to project images 'in the air'. Pena referred the reader to Witelo to understand the making of this image.

This part of optics, which is called catoptrics, teaches how to make a mirror, which does not retain the images of objects, but reflects them in the air. Witelo has written about its composition ... What will prevent cunning women from fooling the eyes of men with this mirror, by making them believe they see ghosts raised from death, while they see the image of some hidden child or statue in the air outside the mirror? Because what seems to exceed all credibility although it is most certain is that, if a cylindrical mirror is placed inside a room closed from all sides, and if a mask, or a statue, or whatever else, is placed outside this room, so that there is a fissure in the window or in the door of this room, through which the rays from the mask penetrate [into the room] to the mirror, then the image of the mask, placed outside the room, will be observed inside the room hanging

7) See, for example, 'images in the air' mentioned in John Dee, The Mathematicall Praeface to the Elements of Geometrie of Euclid of Megara (1570) (New York, 1975), b.jv; Vitellonis Mathematici doctissimi peri optikes, eds., Georg Tannstetter and Petrus Apianus (Nuremberg, 1535), the editors' introduction on the first page.

8) Kepler, Gesammelte Werke, 4: 341.

9) For Petrus Ramus geometry was the "art of measuring well." Along the same lines, in the Opticae libri quatuor ex voto Petri Rami (Kassel, 1606), Ramus and his student Frederic Risner defined optics as "ars bene videndi." For Ramus, see R. Hooykaas, Humanisme, science et réforme: Pierre de la Ramée (1515-1572) (Leiden, 1958), 58-59. See Risner, Opticae libri quatuor, 3: "Optica est ars bene videndi. Optica suo fine definitur, qui est bene videre, id est, de veritate $\&$ fallacia visibilium accurate $\&$ exquisite judicare." 
in the air, and, since the reflections from these mirrors are highly deformed and show a misshapen image of a beautiful thing, how hideous and terrible will the image seem of a mask prepared to arouse horror and consternation. ${ }^{10}$

Pena's reference is to proposition 60 of book 7 of Witelo's Perspectiva: "it is possible to set up a convex cylindrical or conical mirror in such a way that someone looking [into it] can see the image of a particular object that is out of sight [floating] in the air outside the mirror." 11 It is important to realize that Witelo did not speak of a projected image, a concept which was alien to perspectivist optics. The image in the air is still perceived in the mirror; "in the air" referred to a geometrical location, a location in visual space, not physical space. A. Mark Smith has shown that "what Witelo really means in this proposition, however, is that the image will be located behind the reflecting surface at a point outside the circle of curvature defining the invisible portion of the mirror." 12 A diagram showing the location of an image outside a convex mirror in this geometrical sense is found, for example, in Della prospettiva, a man-

10) Jean Pena, "De usu optices Praefatio," Petrus Ramus-Audomarus Talaeus: Collectanae praefationes, epistolae, orationes, ed. Walter J. Ong (Hildesheim, 1969), 140-158, 157: "Docet enim ea Optica pars, quae Catoptrice dicitur, speculum componere, quod objectorum imagines non in se retineat, sed in aëre rejiciat: de cujus compositione \& Vitellio scripsit, \& nos aliquid dicemus (favente Deo) cùm Catoptrica explicabimus. Quid ergo prohibet mulieres versutas hoc speculo, hominum oculos ludificare, ut evocatos manes mortuorum se videre existiment, cùm tamen aut pueri aut statuae alicujus delitescentis simulacrum in aëre extra speculum videant? Nam quod certissimum quidem est, fidem tamen omnem videtur excedere, Si Cylindricum speculum in cubiculo undecunque clauso statuatur, extra autem cubiculum ponatur larva, aut statua, aut quidlibet aliud, ita tamen ut in fenestra vel ostio cubiculi sit rimula aliqua, per quam radii à larva in speculum irrumpant, imago larvae extra cubiculum positae, intra cubiculum cernetur in aëre pendens. \& cùm reflexiones à speculis illis nonnihil deformes sint, ut rei speciosae deformem imaginem ostentent, quàm terra $\&$ terribilis videbitur imago larvae ad horrorem \& consternationem comparatae?"

11) Frederic Risner, Opticae Thesaurus Alhazeni Arabis libri septem, nunc primùm editi. Eiusdem liber de crepusculis et nubium ascensionibus. Item Vitellionis Thuringopoloni libri X, ed. David C. Lindberg (New York and London, 1972), 308-309: "Possibile est speculum columnare vel pyramidale convexum taliter sisti ut intuens videat in aere extra speculum imaginem rei alterius non vise."

12) Smith, "Reflections on the Hockney-Falco Thesis," 178-179. 
uscript of the early fifteenth century attributed to Giovanni Fontana (see fig. 1). However, in another manuscript, entitled Bellicorum instrumentorum liber, the same author pictured a kind of magic lantern designed to project images of demons, apparently to terrify the enemy, in the air in a physical sense (see fig. 2). Fontana's images visualize the confusion between 'images in the air' in the perspectivist tradition of optics and images instrumentally projected in physical space (air).

Another striking characteristic of Fontana's image is its devilish content, which is significant beyond its possible role in military tactics. Monsters and demons were the dominant images which magicians produced. It is, in this connection, interesting to note also that the image in the air of which Pena spoke in De usu optices, as quoted above, was "highly deformed." "How hideous and terrible will the image seem of a mask prepared to arouse horror and consternation," Pena added. In the sixteenth and early seventeenth centuries the 'images in the air', and the optical apparatus producing them, became central objects of contestation in the negotiation of the boundaries between natural and demonic magic. ${ }^{13}$ The monstrous or devilish content of the 'images in the air' seems to point to the agency of demons in the production of these images, but others turned to these 'images in the air' precisely to unmask the claims of demonic magic. For example, Pena claimed that one of the uses of optical knowledge consisted of the unmasking of the forgery of magicians involved in catoptromancy, divination and demonic magic. He argued that alleged sorcerers' illusionist tricks were based on nothing but natural optical knowledge.

What should someone fear who has learned from optics that it is possible to construct a mirror, in which one and the same thing is seen one hundred times? ... Someone who understands that it is possible to place a mirror so that in it you see those things which happen in the streets and houses of strangers; who knows that there is a determined place, at which, if you look into a concave mirror, you will

13) Elsewhere I have discussed this more extensively. See Sven Dupré, "Images in the Air: Optical Games, Magic, and Imagination," in Christine Goettler and Wolfgang Neuber, eds., Spirits Unseen: The Representation of Subtle Bodies in Early Modern European Culture (Leiden, 2007), 71-92. 


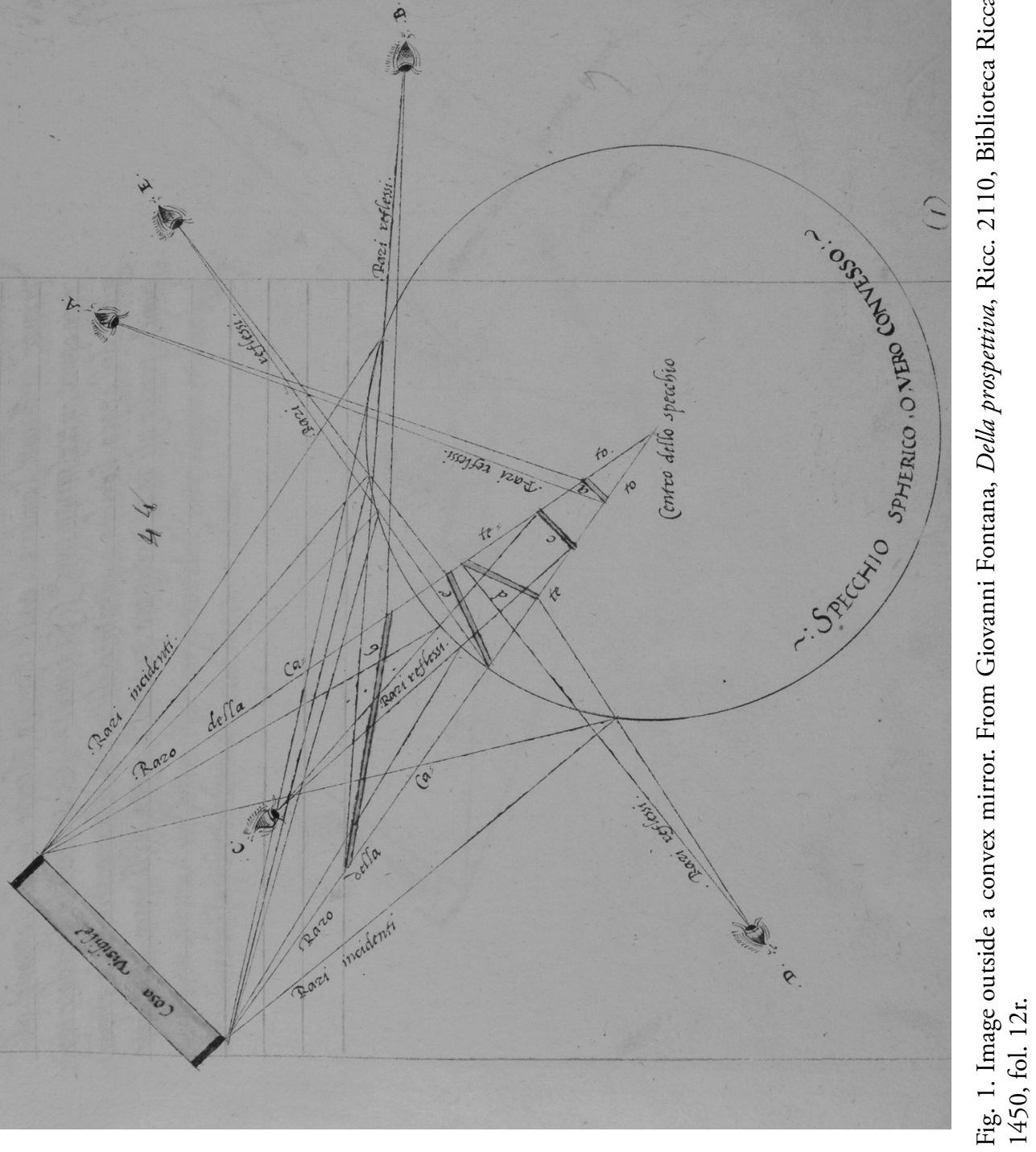




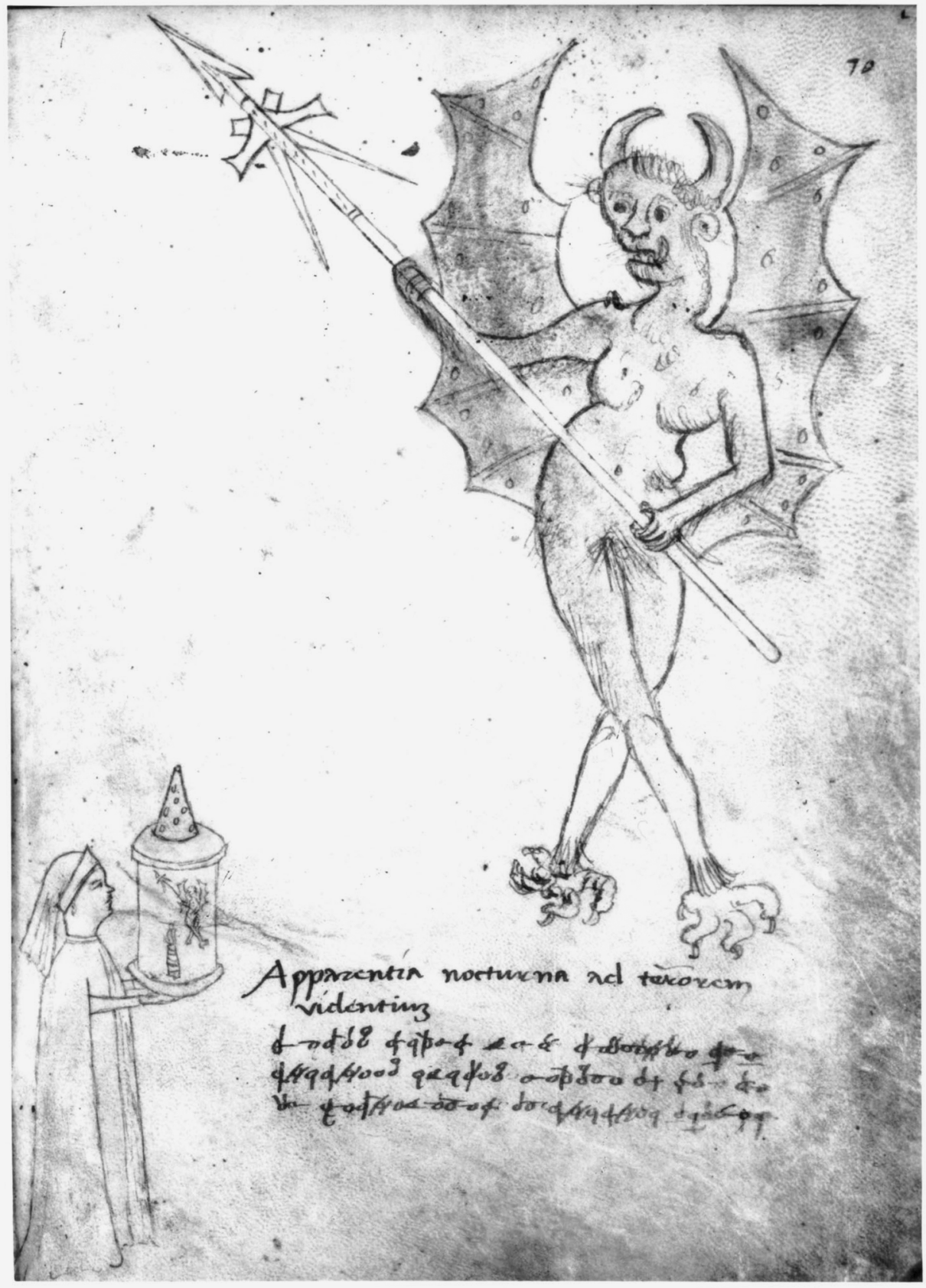

Fig. 2. A magic lantern. From Giovanni Fontana, Bellicorum instrumentorum liber, Cod. Icon. 242, Bayerische Staatsbibliothek, Munich, 1420-1440, fol. 70r. 
see but your eye; who knows that out of plane mirrors a mirror can be constructed so that he who looks into it, sees his image flying-tell me: he who understands all these things from optics, ... does he not distinguish forgery and imposture from the truly physical things? ${ }^{14}$

Pena allowed the "truly physical things" of natural magic, which Della Porta defined as "the practical part of natural philosophy, which produceth her affects by the mutual and fit application of one natural thing unto another," but he was opposed to another kind of magic, which Della Porta called "sorcery," in which magicians allegedly used demons. ${ }^{15}$ Only those ignorant of the optical knowledge at the basis of illusionistic games will believe that a demonic agency is responsible for their production, Pena argued. Authors like Pena, who unmasked the claims of demonic magic, found allies in those who reduced witchcraft to the creation of optical illusions. For example, in The Discoverie of Witchcraft (1584), Reginald Scot undermined theories of witchcraft arguing that witches' powers were based on optical knowledge. ${ }^{16}$

If I affirme, that with certeine charmes and popish praiers I can set an horsse or an asses head upon a man shoulders, I shall not be beleeved; or if I doo it, I shall be thought a witch. And yet if J. Bap. Neap. [Della Porta] experiments be true, it is no difficult matter to make it seeme so. ${ }^{17}$

14) Pena, "De usu optices," 158: "Quid enim reformidabit is qui ex Opticis didicerit, speculum construi posse, in quo unus $\&$ idem videat sui centum aut eo plures imagines choreas ducentes? Qui intelligat speculum ita collocari posse, ut in eo videas ea quae fiunt $\&$ in vicis $\&$ in alienis aedibus? Qui sciat certum esse locum, \& quo si inspicias speculum concavum, tuum oculum tantummodo visurus sis? Qui sciat speculum è planis speculis ita construi posse, ut qui se in eo aspiciat, suam imaginem volantem videat? Cedo, qui ista ex Opticis intelliget, nonné mulierum Thessalicarum praestigias facilè agnoscet? Nonné fucum $\&$ imposturam à rebus verè physicis distinguet?".

15) John Baptista Porta, Natural Magick, ed. Derek J. Price (New York, 1957), 1.

16) Stuart Clark, Thinking with Demons: The Idea of Witchcraft in Early Modern Europe (Oxford, 1997), 249.

17) Reginald Scot, The Discoverie of Witchcraft, ed. B. Nicholson (London, 1886), 257258. 
To illustrate his point, Scot pointed to 'images in the air' produced by wonderful mirrors. ${ }^{18}$

Talk of the monstrous or devilish deformation of these images in the air also contained significant references to the subtance of which these were thought to be made. In contemporary theories of demonology demons were often considered to be made of spirits, precisely the substance that was also directly affected by the imagination, one of the internal senses. ${ }^{19}$ The demonic content of the images in the air' identifies these images as products of the imagination. These monstrous 'images in the air' were thus fundamentally psychological, and as such, they were paradigmatic of optical imagery in the perspectivist tradition of optics. With regard to the definition of an image in this tradition, Kepler stressed: "An image [imago] is the vision of some object conjoined with an error of faculties contributing to the sense of vision. Thus, the image is practically nothing in itself, and should rather be called imagination." ${ }^{20}$

Pena's De usu optices highlighted the connection between optical experiments producing images and the causes of these 'images in the air' already established in the perspectivist tradition of optics. Pena's program is similar to that of Secretum philosophorum, a late thirteenth or fourteenth-century 'book of experiments'. One of the experiments showed precisely how to convert a convex glass mirror into a concave mirror to make an image appear in the air.

You can also make a mirror out of a convex mirror in which an image will appear outside, and this is how it is done. Take an ordinary (that is, a convex one) and scrape off the lead and put it in a box which is not too deep, so that the convexity is towards the bottom of the box, and the concavity is outwards. Then put something dark between the bottom of the box and the mirror, such as a black

18) Ibid., 258-259.

19) Katherine Park, "The Organic Soul," in Charles B. Schmitt, Quentin Skinner, and Eckhard Kessler, eds., The Cambridge History of Renaissance Philosophy (Cambridge, 1988), 464-484, 469. See also Koen Vermeir, "The 'Physical Prophet' and the Powers of the Imagination. Part I: A Case-Study on Prophecy, Vapours and the Imagination (1685-1710)," Studies in History and Philosophy of Biological and Biomedical Sciences, 35 (2004), 561-594.

20) Kepler, Gesammelte Werke, 2: 64. Translation in Kepler, Optics, 77, my italics. 
cloth or some such thing, and do this so that the visual ray is better reflected. Then if you attentively gaze in the mirror, you will see your image outside the box, in the air between you and the mirror. An image also appears outside in columnar and pyramidal mirrors, as is taught in perspective. ${ }^{21}$

Excerpts of the Secretum philosophorum were widely circulated and copied in the fifteenth century. This experiment, in particular, appeared alongside a fifteenth-century English copy of Roger Bacon's De multiplicatione specierum and Perspectiva. ${ }^{22}$ The connection that this manuscript established with the work of Bacon was not coincidental. Goulding has argued that the Secretum philosophorum might be read as a tribute to Bacon's attempt to bring 'experiments' into the philosophical curriculum. ${ }^{23}$ However, the fact that Pena felt the need to re-establish the connection between optical experiments and the causes of 'images in the air' in perspectivist optics indicates that it was easy for this connection to be loosened to the extent that these experiments became singular events disconnected from optical theory. ${ }^{24}$ Whenever that happened, as for example in Fontana's Bellicorum instrumentorum liber (disconnected from his Della prospettiva) or in Della Porta's Magia naturalis, it was easy to misinterpret 'images in the air' as images physically floating in the air or truly experimentally generated projected images. Kepler was able to sort out this confusion, however, only by giving specific meaning to the notion of experiment. What was the status and meaning of the experiment inside the Kunstkammer in Kepler's Paralipomena?

21) Robert Goulding, "Deceiving the Senses in the Thirteenth Century: Trickery and Illusion in the Secretum philosophorum," in Charles Burnett and W.F. Ryan, eds., Magic and the Classical Tradition (London and Turin, 2006), 135-162, 156.

22) Ibid., 142.

23) Ibid., 139.

24) For this notion of 'experiment' in a medical context, see Michael McVaugh, "The Experimenta of Arnald of Villanova," Journal of Medieval and Renaissance Studies, 1 (1971), 107-118. 


\section{Kepler in the Dresden Kunstkammer}

In this section I will argue that the status of optical experiments inside the Kunstkammer was that of play. At the courts in Prague and Dresden courtiers participated in optical games with optical objects collected in the local Kunstkammer. ${ }^{25}$ As Kepler wrote in a letter to the Dresden court in December 1610, Rudolf II, his patron in Prague, was highly interested in optical games that made use of the image-forming capacities of lenses, mirrors and the camera obscura as discussed in Della Porta's Magia naturalis. ${ }^{26}$ A crystal ball, a gift presented to the Elector of Saxony, August I, by the Duke of Savoy in 1580 and prominently displayed in the most important room of the Dresden Kunstkammer, was most likely also intended to be used in such social play or games centered around the "effects and powers of the crystal." ${ }^{27}$ Images, including those anamorphically deformed and monstrous apparitions 'in the air' produced by mirrors inside the Kunstkammer, were thus considered games or forms of social play.

But what does this tell us about these 'images in the air'? The playful context of production of these images is significant with respect to their epistemological status. Paula Findlen has shown that

25) In this connection, it should not surprise us that Horst Bredekamp has characterised the Kunstkammer as a Spielkammer. See Horst Bredekamp, "Die Kunstkammer als Ort spielerischen Austauschs," in Thomas W. Gaehtgens, ed., Künstlerischer Austausch. Artistic Exchange. Akten des XXVIII. Internationalen Kongresses für Kunstgeschichte Berlin, 15.-20. Juli 1992 (Berlin, 1993), 65-78.

26) Kepler to Anonymous in Dresden, 18 December 1610, in Kepler, Gesammelte Werke, 16: 347. For the intellectual climate at the Prague court of Rudolf II, especially for the importance of Della Porta and his natural magic, see R.J.W. Evans, Rudolf II and his World: A Study in Intellectual History 1576-1612 (Oxford, 1973), 197.

27) The specialized book collection within the Kunstkammer included a manuscript giving a Description of the Effects and Powers of the Crystal Given by the Duke of Savoy to the Elector, Duke August of Saxony. The manuscript is only known from its title in the early Kunstkammer inventories. See Helen Watanabe-O'Kelly, Court Culture in Dresden: From Renaissance to Baroque (New York, 2002), 254. The crystal ball itself is preserved in the Grünes Gewölbe of the Dresden State Art Collections. For more information, see Sven Dupré and Michael Korey, "Inside the Kunstkammer: The Circulation of Optical Knowledge and Instruments at the Dresden Court," forthcoming. 
in this period no distinction was made between ludus, as social play, and lusus, as intellectual play (such as the jokes of nature or of knowledge that populated the contemporary collections and texts). ${ }^{28}$ The category of lusus was used to grasp the preternatural. The realm of the preternatural consisted of those 'wonders' or marvellous events and objects that fell outside the ordinary course of nature, but of which the cause was nevertheless not supernatural. The notion of lusus incorporated the vocabulary of optical illusion. ${ }^{29}$ In the earlyseventeenth century works of Jesuits and anamorphoses-producing Minims, such as Jean-François Niceron, ludere and illudere went together. For example, the images of Giuseppe Arcimboldo, highly appreciated at the court in Prague, were conceptualized as 'serious jokes' ${ }^{30}$ In this sense, we should also recognize the jocular or preternatural character of the 'images in the air'.

In Dresden the organization of the optical objects in the Kunstkammer was closely connected to ideas about the kind of optics that a court mathematician should practice. ${ }^{31}$ In a tradition that saw itself derivative of Hans Lencker's work on perspective, optics was considered at the Dresden court to be a mathematical art productive of perspectival mirabilia. It was explicitly opposed to the kind of optics that natural philosophers primarily concerned with celestial or astronomical applications of optical knowledge thought interesting, which was how optics was taught at Wittenberg, the most important university on Saxon territory. Optical objects acquired for the Kunstkammer were assimilated to this image. When in the early seventeenth century newly invented telescopes arrived in Dresden, Lucas Brunn, the court mathematician and curator of the Kunstkammer, displayed them amidst anamorphoses and an instrument of his own invention to produce such images.

28) Paula Findlen, "Jokes of Nature and Jokes of Knowledge: The Playfulness of Scientific Discourse in Early Modern Europe," Renaissance Quarterly, 43 (1990), 292331.

29) Ibid., 322-324.

30) Thomas DaCosta Kaufmann, “Arcimboldo’s Serious Jokes: 'Mysterious but Long Meaning'," in Karl-Ludwig Selig, ed., The Verbal and the Visual: Essays in Honor of William S. Heckscher (New York, 1990), 59-86.

31) Sven Dupré and Michael Korey, "Inside the Kunstkammer," forthcoming. 
I do not wish to argue that Kepler should be thought of as a court mathematician of the same kind as Brunn. In fact, although Kepler flirted with the Dresden court during the period of his life when his position in Prague became insecure, entertained a patronclient relationship with the Elector of Saxony in the first decade of the seventeenth century, and at one point was even considered for a chair of mathematics at the university of Wittenberg, he was never hired as a mathematician at the Dresden court. ${ }^{32}$ More importantly, Kepler did not share Brunn's image of optics; for him, the astronomical and the philosophical contexts were too important to allow for that. Nevertheless, I wish to argue that Kepler borrowed the playful characteristics of Dresden's optical culture for his own purposes.

In his Somnium, posthumously published in 1634, Kepler narrated how he performed magical optical games inside the camera obscura at the beginning of his astronomical observations:

This also is a magical ceremony. ... During those years in Prague I often carried out a special procedure in connection with a certain observation. Whenever men or women came together to watch me, first, while they were engaged in conversation, I used to hide myself from them in a nearby corner of the house, which had been chosen for this demonstration. I cut out the daylight, constructed a tiny window out of a very small opening, and hung a white sheet on the wall. Having finished these preparations, I called in the spectators. These were my ceremonies, these were my rites ... In capital letters I wrote with chalk on a black board what I thought suited the spectators. The shape of the letters was backwards (behold the magical rite), as Hebrew is written. I hung this board with the letters upside

32) In a letter of December 1610 to an anonymous correspondent at the Dresden court Kepler hinted that he was prepared to move to Dresden. See Kepler, Gesammelte Werke, 16: 353. In the years prior to this letter Kepler had offered several of his publications, including his De stella nova (1606) and Astronomia nova (1609) to Christian II, the Elector of Saxony. See Jürgen Helfricht, "Johannes Kepler und seine Beziehungen zu Dresden, " in Astronomiegeschichte Dresdens (Dresden, 2001), 33-37, 35. In 1611 Kepler was considered for the professorship of higher mathematics at the university of Wittenberg, over which the Dresden court held authority, but the Oberkonsistorium decided that to go after Kepler for this position was to aim too high and appointed instead Kepler's colleague Ambrosius Rhodius. See the documents gathered in Kepler, Gesammelte Werke, 19: 349-350. 
down in the open air outside in the sunshine. As a result what I had written was projected right side up on the wall within. ... The spectators enjoyed [these games] all the more for realizing that they were games. ${ }^{33}$

In Paralipomena Kepler explicitly also defined the experiment inside the camera obscura in terms of play. He concluded his description of the experiment by admitting that "the games [ludi] can be made more elaborate." ${ }^{34}$ While the irony of the autobiographical passage in Somnium is undeniable, this tone is missing from his description of the optical experiment inside the Dresden Kunstkammer in Paralipomena. Were the games in Somnium only the prelude to the astronomical observations that really mattered for Kepler, the games in Paralipomena were important in themselves, not in contrast to observations to follow. But why then did Kepler grant the status of ludi to the experiment inside the camera obscura of the Kunstkammer? Why was it not enough that it was an experimentum? Why did it explicitly also need to be ludi for Kepler?

The active intervention necessary to produce these images is not the most novel aspect of Kepler's use of experiment. ${ }^{35}$ In fact, it is worth pointing out that he portrayed the experimentum inside the Dresden Kunstkammer as an experience to which he was only a witness, and a passive one, as far as we can tell. We learn that a custodian, less knowledgeable than Kepler, performed the experiment, when Kepler notes about the 'image in the air' which he saw in the darkened room of the Dresden Kunstkammer that "what I, steeped in demonstrations, stated that I had seen, the others denied. I there-

33) Kepler, Gesammelte Werke, 11.2: 338. Translation in Johannes Kepler, Kepler's Somnium: The Dream, or Posthumous Work on Lunar Astronomy, trans. Edward Rosen (Madison, 1967), 57-58. For the jocular character of Kepler's magical games in Somnium, see Raz Chen-Morris, "Shadows of Instruction: Optics and Classical Authorities in Kepler's Somnium," Journal of the History of Ideas, 66 (2005), 223-243.

34) Kepler, Gesammelte Werke, 2: 164-165. Translation in Kepler, Optics, 194.

35) For a discussion of the 'non-interventionist fallacy' of much recent history of early modern science, interestingly in this connection, often pointing to evidence from optical experimentation, see William R. Newman, Promethean Ambitions: Alchemy and the Quest to Perfect Nature (Chicago and London, 2004), 238-289. 
fore attribute it, not to the overseer's intent, but to chance." 36 It is not the interventionist aspect that seems to interest Kepler. The custodian produced the experimental result (the 'image in the air') by chance, and Kepler was the only one who saw it! Neither of these factors were, however, presented as impediments to knowledge generation or proof.

The ludic aspect of the experiment was important for Kepler, because it allowed him to compare and to differentiate the experiment inside the Dresden Kunstkammer from the 'experiments' in Della Porta's Magia naturalis. Della Porta's 'experiments' were also games, but the ludi in Kepler's Paralipomena were not mere entertainment like Della Porta's. Nor were they singular events. The experiment inside the Dresden Kunstkammer was part of Kepler's argument in Paralipomena. It had a point-a theoretical point about optical imagery. In the context of the medical practice of Anna of Saxony, the wife of Elector August, founder of the Dresden Kunstkammer, Alisha Rankin has recently argued for a court experimentalism as a middle ground between the medieval notion of experimentum as a singular event and its later use in which it became connected with the generation and justification of natural philosophical theories in the 'experimental philosophy' ${ }^{37}$ In the case of Kepler-perhaps not coincidentally situated in the same courtly context which Rankin discussed-the ludic character of the experiment allowed Kepler to connect the experimentum to a theory of optical imagery.

While the experiment allowed Kepler to conceptualize projected images (which were only empirically familiar from eclipse observations or 'experiments' such as Della Porta's) in a new theory of optical imagery, he nevertheless did not think that his newly invented concept of pictura was universally applicable, and he would not proceed to use it for understanding telescopic images in Dioptrice (1611)..$^{38}$ The ludic character of the experiment also allowed Kepler

36) Kepler, Gesammelte Werke, 2: 164-165. Translation in Kepler, Optics, 194.

37) Alisha Rankin, "Becoming an Expert Practitioner: Court Experimentalism and the Medical Skills of Anna of Saxony (1532-1585)," Isis, 98 (2007), 23-53.

38) See Malet, "Keplerian Illusions," 6-21. 
to differentiate between picturae and images in the air. Kepler did not simply deny the appearance of images in the air. In fact, the experiment inside the Dresden Kunstkammer showed that such images could appear inside the camera obscura. However, in contrast to the picturae, the images in the air did not follow the geometrical rules of the game. Kepler pointed out that the image in the air appearing inside the Dresden Kunstkammer was a product of chance. Moreover, he insisted that of all participants in the experiment he was the only one who actually perceived this image. In other words, the experiment allowed Kepler to describe the 'image in the air' as preternatural, as it fell outside the normal course of image-making nature. In this sense the experiment supported the co-existence of imagini and picturae without conceptual conflict.

\section{Kepler's Reading of Della Porta's Magia naturalis}

We are now in a position to examine in more detail Kepler's reading of Della Porta's Magia naturalis. The two passages in Della Porta's Magia naturalis to which Kepler referred are chapters 10 and 13 of book 17, in which Della Porta made images appear in the air with a convex lens or crystal ball. In our discussion of Pena's De usu optices and of his reference to the discussion of images in the air in Witelo's Perspectiva, we have seen that the image was produced in a cylindrical mirror inside a camera obscura, but it is indeed worth stressing that 'in the air' referred likewise to the geometrical locus of images (by application of the cathetus rule) in concave mirrors, aqueous globes, crystal balls or convex lenses. However, the cases of aqueous globes (or crystal balls) presented some specific problems which do not occur in single surface optical objects. They arose from problems of application of the cathetus rule to determine the geometrical location of images in optical objects with more than one refracting surface, such as a globe.

Della Porta's approach to this problem is contained in De refractione (1593). In this treatise Della Porta accepted the location of the perceived image, which is at the surface of the lens or crystal ball. Nevertheless, he attempted to offer a demonstration for it by 
applying the cathetus rule to image formation in a refracting sphere. ${ }^{39}$ The cathetus rule was the accepted perspectivist means to find the geometrical, not the perceived locus. Moreover, its application here was completely arbitrary, because Della Porta did not know how to apply it to a case with more than one refracting or reflecting surface (fig. 3). He assumed that the ray $\mathrm{CB}$ is refracted to $\mathrm{E}$, where it is again refracted to the eye at $\mathrm{A}$. To locate the image of $G$, he took the cathetus from $G$ through the center $D$, and, then, located the image in $\mathrm{E}$, at the surface of the refracting sphere, where it intersects the refracted ray BE. Thus, for Della Porta in De refractione there were no images 'in the air' outside the crystal ball. He was interested only in perceived images.

Kepler had not seen a copy of Della Porta's De refractione. He had access to Della Porta's Magia naturalis only, in which Della Porta did have 'images in the air'. Kepler argued that in the section "with a convex crystalline lens, to see an image hanging in the air," Della Porta created confusion between the image seen between this lens and the eye (in the air) and the projected image, because he wrote that "if you will place a piece of paper in the way, you will see clearly that a lighted candle appears to be burning upon the paper." ${ }^{40}$ Della Porta assimilated projected images to the category of 'images in the air'. Kepler tried to sort out the confusion by situating the third section of chapter 5 of his Paralipomena inside the camera obscura. He opened this chapter with a description of image formation in a crystal ball in a room-size camera obscura. Unlike Della Porta, he made a clear distinction between perceived and projected images:

For if one were to stand with a crystalline or aqueous globe of this kind in some room next to a glazed window, and provide a white piece of paper behind the globe, distant from the edge of the globe by a semidiameter of the globe, the glazed window with the channels overlead with wood and lead ... are depicted with

39) Giovanbattista della Porta, De refractione optices parte libri novem (Naples, 1593), 49. See Sven Dupré, "Ausonio's Mirrors and Galileo’s Lenses: The Telescope and Sixteenth-Century Practical Optical Knowledge," Galilaeana: Journal of Galilean Studies, 2 (2005), 145-180, 168.

40) Kepler, Gesammelte Werke, 2: 164. Translation in Kepler, Optics, 193. 


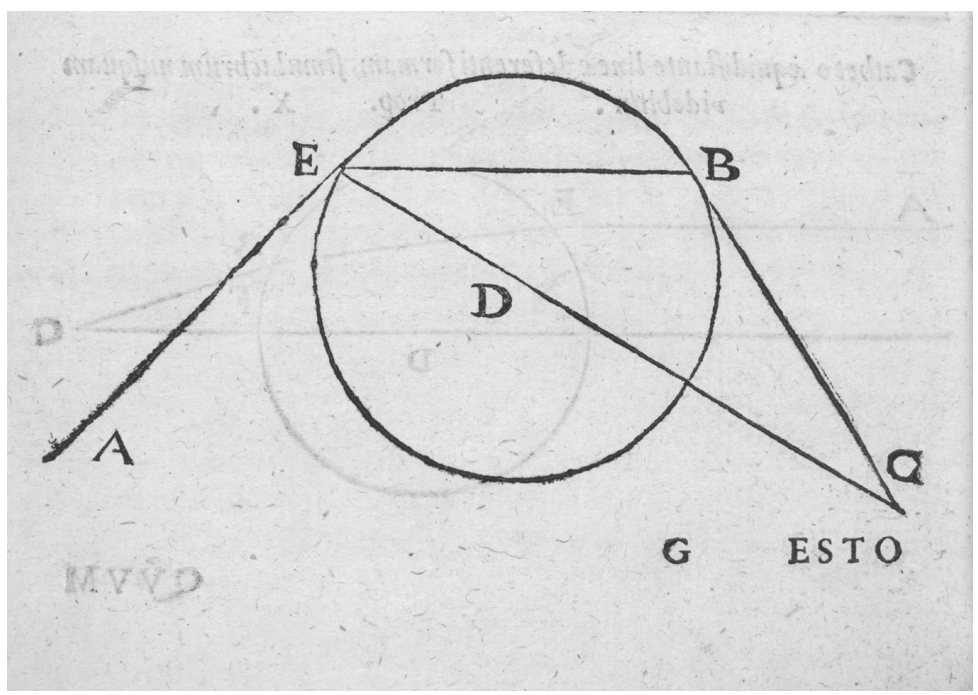

Fig. 3. The application of the cathetus rule to image formation in a refracting sphere, from Giovanbattista Della Porta, De refractione (Naples, 1593), 1568/1824. By permission of the British Library.

perfect clarity upon the paper, but in an inverted position. The rest of the objects do the same thing, if the place be darkened a little more ... whatever things are able to reach through the breadth of the little window or opening to the globe are all depicted with perfect clarity and most pleasingly through the crystalline upon the paper opposite. And while the picture appears at this distance uniquely (that is, a semidiameter from the globe to the paper), and nearer and farther there is confusion, nevertheless, exactly the opposite happens when the eye is applied. For if the eye be set at a semidiameter of the globe behind the glass, where formely the picture was most distinct, there now appears the greatest confusion of the objects represented through the glass. ... If the eye comes to be nearer to the globe, it perceives the objects opposite erect and large, ... if it on the other hand recedes farther from the globe than the semidiameter of the globe, it grasps the objects with distinct images, inverted in situation, and small, and clinging right to the nearest surface of the globe. ${ }^{41}$

Note that Kepler in this passage naturally located the perceived image at the surface of the globe, like Della Porta in De refractione. He was less interested here in 'images in the air'. Surprisingly, they

41) Kepler, Gesammelte Werke, 2: 162. Translation in Kepler, Optics, 191, my italics. 
returned, however, in the first propostion when he attempted to find the geometrical locus of an image in an aqueous globe by applying a new method replacing the cathetus rule. In the third chapter of his Paralipomena Kepler rejected the cathetus rule, because the cathetus had no meaning within his physics of light. ${ }^{42}$ To replace the cathetus rule he formulated a more general rule for image location, based on the 'distance-measuring triangle' to explain the judgment of distances. ${ }^{43}$ Kepler argued that distances are determined by a triangle that uses the distance between our two eyes, the base of the triangle, and the angle of convergence of the axes of the eyes, converging toward the object, that is, the vertex of the triangle. Since the eye is unaware of any change of direction of rays before they enter the eye, it judges objects to be in the place where the reflected or refracted rays come from. Thus, Kepler argued, "the genuine place of the image is that point in which the visual rays from the two eyes meet, extended through their respective points of refraction or reflection." ${ }^{4} 4$ In the first proposition of the fifth chapter he applied the principle that the image is at the vertex of the optical triangle formed with two eyes to image formation in a sphere filled with water (fig. 4). ${ }^{45} \mathrm{He}$ located the image of point $A$, seen through the sphere filled with water EFG with two eyes B and $\mathrm{C}$ at $\mathrm{D}$, the intersection of the rays AEFC and AGHB. It is evident that in this proposition Kepler located the image in the air.

However, in the following propositions, Kepler adduced reasons why the image is seldom seen at D. In proposition 5 he finally retreated from the claim in his first proposition. He wrote: "In front

42) For a discussion of Kepler's rejection of the cathetus rule, see Raz Dov Chen-Morris and Sabetai Unguru, "Kepler's Critique of the Medieval Perspectivist Tradition," in Gérard Simon and Suzanne Débarbat, eds., Optics and Astronomy: Proceedings of the XXth International Congress of History of Science (Liège, 20-26 July 1997) (Turnhout, 2001), 83-92; Gérard Simon, Structures de pensée et objets du savoir chez Kepler (Paris, 1976), 464-477; Shapiro, "The Foundations of the Theory of Optical Imagery," 122 124.

43) Kepler, Gesammelte Werke, 2: 66-67.

44) Ibid., 2: 72 (translation in Kepler, Optics, 85).

45) Ibid., 2: 162-163. 


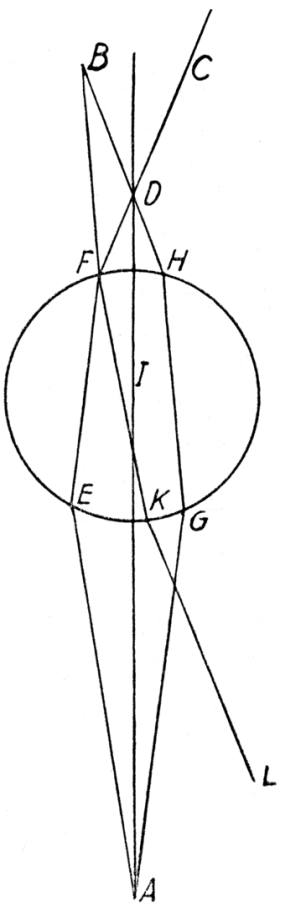

Fig. 4. Image location in a refractive sphere with two eyes, from Johannes Kepler, Gesammelte Werke, ed. Walther von Dyck, Max Caspar, Franz Hammer, 19 vols. (Munich, 1937-), 2: 165.

of an aqueous ball or globe there is no place for the image of an object hiding behind the globe." ${ }^{6}$ Kepler used the distinction between projected images and images in the air to criticize Della Porta's account of image formation, which failed to make this distinction.

Pertinent to this is what Porta had taught in chapter 10 preceding, 'with a convex crystalline lens, to see an image hanging in air'.... For this reason, he adds, 'If you will place a piece of paper in the way, you will see clearly that a lighted candle appears to be burning upon the paper.' That is, the image will be seen weakly and hardly at all in the bare air itself, by Porta's admission. But if you put a piece of paper in the way-if, I say, you interpose a piece of paper between the

46) Ibid., 2: 164 (translation in Kepler, Optics, 193). 
lens and the sense of vision (for, with me, Porta here is still speaking about the image, not yet about the picture, of which this is true, as will be clear below), the image will now appear, not hanging in air, but fixed on the paper. For the paper, striking the eyes more obviously, steadies them on the place of the image, so that they may be turned towards each other in that direction. And nonetheless, because the paper is then brighter than the image, the paper will be seen primarily, the image secondarily. For it is not mathematical dimensions alone that create the image, but also, and much more, the colors and lights and physical causes. ${ }^{47}$

This is not to say that Kepler considered it impossible to perceive images in the air at the locus indicated in his proposition 1. This is clear from the continuation of this passage.

If you should focus the eyesight upon one place, namely, upon the place of the image previously investigated, as it has been described in prop. 1 of this chapter, when a clearly visible object is placed nearby, then the eyes coming together upon this object, will also see the required image secondarily. ${ }^{48}$

It is here that the experiment inside the camera obscura became important again for Kepler. In truly exceptional circumstances, like in the ones that Kepler witnessed inside the Dresden Kunstkammer, Kepler did perceive the image in the air. Nevertheless, Kepler immediately cut off his report of the experiment by stating that he would only discuss "things that are more obvious and ready at hand." 49 In what followed Kepler discussed pictures or projected images: "Since hitherto an Image [Imago] has been a Being of the reason, now let the figures of objects that really exist on paper or upon another surface be called pictures [Pictura]." ${ }^{50}$ Kepler located the picture at the intersection of pencils of rays along the axis of the sphere filled with water-a location which was based on his concept of a refracting focus. He demonstrated that

through a globe of a denser medium, any point more remote than the intersections of parallels strongly depicts itself upon paper, located at the last boundary

47) Ibid., 2: 164 (translation in Kepler, Optics, 193-194).

48) Ibid. (translation in Kepler, Optics, 194).

49) Ibid., 2: 165 (translation in Kepler, Optics, 194).

50) Ibid., 2: 174 (translation in Kepler, Optics, 210). 
of the intersection of its radiations, not before and not after this point; and the picture comprising all the points is seen inverted. ${ }^{51}$

Unlike images, which were products of the imagination, pictures were made by rays of light only.

\section{Conclusion}

Instead of using the experiment inside the Dresden Kunstkammer to decide between two theories of optical imagery, Kepler used it to assign his two types of optical image to two different realms, pictura to the natural and imago to the preternatural, which was the realm of events and objects within nature that fell outside the ordinary course of nature. In this way he minimized the conceptual ambiguity arising from his use of two different concepts of image. If his Paralipomena is ambiguous, it is rather about the locus of the perceived image. Is it seen at the surface of the aqueous globe, like in Della Porta's De refractione, as Kepler correctly claimed at the beginning of section 3 of chapter 5 quoted above? Or is it seen in the air between the globe and the eyes, as Kepler claimed in proposition 1? In the following propositions he was at pains to show that it is impossible to see it physically hanging in the air, only to ultimately claim that he had seen an image in the air in the experiment inside the Dresden Kunstkammer. He was quick to point out, however, that he had been the only one to see it, because he was "steeped in demonstrations," undoubtedly referring to the demonstrations of the geometrical locus of images in the air in the perspectivist tradition of optics. Looked at the experiment inside the Dresden Kunstkammer in this way, Kepler used it to claim the existence of the physically impossible. Although the experiment inside the Dresden Kunstkammer was grounded in a courtly culture of (optical) experimentation, this should remind us of the extent to which the experiment, in the way Kepler reported and used it in Paralipomena, was an experience of reading.

51) Ibid., 2: 176 (translation in Kepler, Optics, 211). 
What did the experiment inside the Dresden Kunstkammer and Kepler's experience of reading Della Porta's experiments in Magia naturalis do for Kepler's new optics? I have argued that the experiment and reading experience was the mechanism by which Kepler succeeded in bringing optical theory from the pre-Keplerian, perspectivist conceptual state in which projected images had no place to their Keplerian and post-Keplerian state in which these images were conceptually integrated into a new theory of optical imagery. It should be made explicit that this does not downplay the importance of Kepler's familiarity with the perspectivist tradition of optics and its concepts nor does it negate the role of the astronomical and artistic contexts to the shaping of Kepler's new theory of vision. However, when it comes to Kepler's theory of optical imagery, the perspectivist tradition and the astronomical and artistic contexts fall short of explaining the conceptual shift that took place in Kepler's Paralipomena. I argue that what should be added to the matrix is Kepler's immersion in the courtly optical cultures of Prague and Dresden. This does not imply that Kepler's optics is to be reduced to its courtly guise. It does show, however, that the concepts (or perhaps better in this case, the conceptual confusion) of Della Porta's Renaissance optics was important for the generation of Kepler's new theory of optical imagery. 